\title{
Analysis on Combustion Process of Ethanol - Diesel Direct Injection Engine with Two-stage Ethanol Injection Ignited by Diesel
}

\author{
Yu Liang, Liying Zhou, Tao Zhang, Jianghe Zou, Deyan Ren, Xiaosha Tang \\ College of Mechanical Engineering, Guiyang University, Guiyang 550005, China \\ Corresponding author e-mail: zhouliying0330@163.com
}

Keywords: ethanol, diesel, two-stage injection, ethanol - diesel dual direct injection, combustion process

\begin{abstract}
A set of GDI system was installed on a F188 single-cylinder, air-cooled and vertical direct injection diesel engine, which was used for ethanol injection, and the mechanical pump injection system of the original diesel engine was used for diesel injection. Ethanol and diesel account for half of the total size respectively, and the total heat energy of the fuel is equivalent to that of the original diesel engine under the same condition. A 3D combustion model is established for the ethanol - diesel direct injection engine. The ethanol injection is adopted with two-stage injection mode, with the first stage injection starting point at $240^{\circ} \mathrm{CA}$ and the second stage injection starting point the same as the diesel injection starting point, $344^{\circ} \mathrm{CA}$. Four conditions featured by the same total two-stage ethanol injection and the first stage injection and second stage injection respectively accounting for $20 \%$ and $80 \%$ (B20L80), $40 \%$ and $60 \%$ (B40L60), 60\% and 40\% (B60L40) and $80 \%$ and $20 \%$ (B80L20) of the total injection are calculated and analyzed. After diesel burning, the mixed ethanol is ignited. The two-stage ethanol injection proportion is different, and ethanol premixing and diffusion combustion proportion in the cylinder is also different, thus affecting the combustion process. The result shows that, with regard to B60L40 and B40L60, cylinder combustion pressure and average temperature are higher, combustion speed is faster, combustion is more sufficient, and combustion process is better. B60L40 has the highest NO generation but the lowest soot generation, and B20L80 has the lowest NO generation but the highest soot generation.
\end{abstract}

\section{Introduction}

Ethanol has been widely appreciated by governments and the business circles around the world. Developed countries such as Europe and the United States, as well as developing countries such as Brazil, India and Indonesia, have developed strategic plans for medium and long-term development of ethanol. In 2005, the Renewable Energy Law was issued in China, which explicitly states that renewable energy including ethanol will be vigorously developed. The China's Medium and Longterm Development Planning for Renewable Energy plans that the annual production capacity of the China's ethanol will reach 10 million tons by 2020 [1].

Our country has formed a certain scale in the preparation of ethanol with non-food crops including cassava, sweet sorghum and xylose residue, and the technology of preparing ethanol with wood lignocellulose including forestry and agricultural residues is becoming more and more mature [2]. Ethanol contains 34.7\% oxygen, its octane value and combustion speed are high, so it is a highly efficient and clean renewable energy source, and a kind of fuel quality improvement agent with high quality. China's ethanol has the largest potential in the massive production of biomass fuel, and its production capacity can play an important role in supplementing the China's petroleum consumption and bring broad application prospects [3].

As ethanol is not mutually soluble with diesel [4], its application in the diesel engine is difficult, therefore, a number of application forms including mixing [5, 6], ethanol injection in the inlet or the cylinder ignited by burning diesel [7] and homogeneous charge ignition by compress combustion occur [8]. Fang Xianzhong, et al. of Jilin University conducted the ethanol - diesel direct injection 
study before, with diesel injection and ethanol injection respectively for the new mechanical pump injection system and the original injection system. The ethanol injection starting point is $1^{\circ} \mathrm{CA}$ behind the diesel injection starting point, diffusion accounts for the main part during ethanol combustion, and $\mathrm{HC}$ and $\mathrm{CO}$ emissions significantly increase when compared with the original diesel engine $[9,10]$.

An electronic control gasoline injection system was installed on the single cylinder diesel engine, which is used for ethanol injection, and the mechanical pump injection system of the original diesel engine is used for diesel injection. The ethanol injection is divided into two stages, with injection in the compressed stroke during the first stage and simultaneous ethanol and diesel injection during the second stage. A 3D combustion model is established to study the combustion process of the ethanol - diesel direct injection engine when the proportion of the two-stage ethanol injection changes.

\section{Combustion Model}

The gasoline electric control direct injection system was installed on the single-cylinder diesel engine, and the engine can separately run with diesel or ethanol - diesel direct injection. The main parameters of the engine are shown in Table 1.

Table1. Summary of engine specifications

\begin{tabular}{|c|c|}
\hline Parameters & Value \\
\hline Type & $\begin{array}{c}\text { Vertical, air cooled, natural aspirating, direct } \\
\text { injection, four-stroke }\end{array}$ \\
\hline Cylinder bore $\times$ stroke $/ \mathrm{mm} \times \mathrm{mm}$ & $88 \times 75$ \\
\hline Length of the connecting rod/mm & 115 \\
\hline Compression ratio & 20.8 \\
\hline Rated rotation speed / r $\cdot \mathrm{min}^{-1}$ & 3000 \\
\hline Combustion chamber type & Type $\omega$ \\
\hline $\begin{array}{c}\text { Diesel supply advance angle ( }{ }^{\circ} \mathrm{CA} \\
\text { in front of TDC) }\end{array}$ & 21 \\
\hline $\begin{array}{l}\text { Inlet valve closing }\left({ }^{\circ} \mathrm{CA} \text { behind }\right. \\
\text { BDC) }\end{array}$ & 54 \\
\hline $\begin{array}{c}\text { Exhaust valve open }\left({ }^{\circ} \mathrm{CA} \text { in front }\right. \\
\text { of BDC) }\end{array}$ & 54 \\
\hline $\begin{array}{c}\text { Number of nozzles of the diesel } \\
\text { injector }\end{array}$ & 4 \\
\hline $\begin{array}{l}\text { Diameter of nozzles of the diesel } \\
\text { injector/mm }\end{array}$ & 0.32 \\
\hline $\begin{array}{c}\text { Number of nozzles of the ethanol } \\
\text { injector }\end{array}$ & 6 \\
\hline $\begin{array}{l}\text { Diameter of nozzles of the ethanol } \\
\text { injector/mm }\end{array}$ & 0.183 \\
\hline
\end{tabular}

As shown in Table 1, the diesel injector has 4 uniform holes, and ethanol injector has 6 nonuniform holes. As the angle between the hole injection direction of two injectors and the cylinder section is different, the whole combustor chamber is adopted for modeling. The fuel center and fuel spray distribution of two fuel injectors are shown in Figure 1. For adopting nephograms for analysis in the future, two sections are defined in Figure 1 (Section A passes through the diesel injector center and Section B passes through the ethanol injector center, these two sections are the symmetrical sections of the injection fuel spray), and the following nephograms are taken from these two sections. The geometric model is drawn by ProE software and divided by Hypermesh software, the mesh is optimized and densified by AVL FIRE, and the dynamic mesh is set for calculation and post-processing analysis. Therefore, the model is the whole combustion chamber, the area close to the nozzle and boundary is densified, with 110,496 meshes at TDC (top dead center) and 348,096 meshes at BDC (bottom dead center). The geometric model and combustion chamber mesh are shown in Figure 2. 


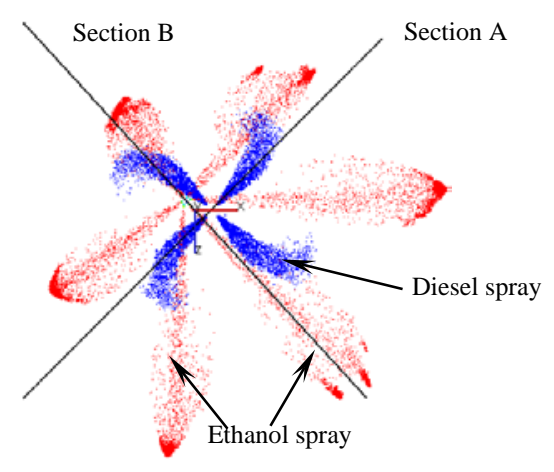

Figure 1. Diesel and ethanol injection position and fuel spray

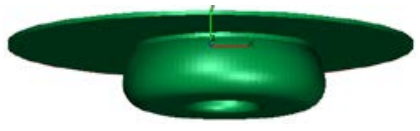

a) top dead center

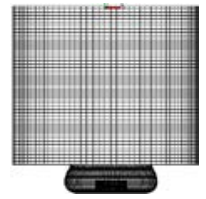

b) bottom dead center

Figure.2 Geometric model at top dead center and combustion chamber mesh at bottom dead center

The kinetic calculation of chemical reaction is carried out with FIRE's own standard ethanol and diesel transportation model, and the main computational model selection is shown in Table 2. Ethanol and diesel account for half of the total size respectively, and the total heat energy of the fuel is equivalent to that of the original diesel engine under the same condition. The ethanol injection is adopted with two-stage injection mode, with the first stage injection starting point at $240^{\circ} \mathrm{CA}$ and the second stage injection starting point the same as the diesel injection starting point, $344^{\circ} \mathrm{CA}$. Four conditions are subject to simulated calculation, and the results show that, though two-stage ethanol injection in four conditions is the same, the percentage of the two-stage injection in the total injection is different. With regard to the 1st condition, the first stage ethanol injection and the second stage ethanol injection account for $20 \%$ and $80 \%$ of the total injection respectively (B20L80), with regard to the 2nd, 3rd and 4th conditions, the ethanol injection during the first stage and the ethanol injection during the second stage account for $40 \%, 60 \%, 80 \%$ and $60 \%, 40 \%, 20 \%$ of the total injection respectively, namely (B40L60), (B60L40) and (B80L20). As injection of the first stage ethanol is carried out immediately after the inlet valve is turned off, ethanol has a long time to gasify and facilitate the formation of combustible mixture. However, the injection of the second stage ethanol is carried out together with diesel injection, and ethanol will be dominated by the diffusion combustion. This paper focuses on the analysis and discussion of the effect on the combustion process of the ethanol - diesel direct injection engine when the ethanol distribution proportion is different during the two-stage.

Table 2. Computational models

\begin{tabular}{cc}
\hline Computational Model & Selection \\
\hline Turbulence model & K-Zeta-F \\
Fuel wall interaction model & Bai Gosman \\
Fuel evaporation model & Multi-component \\
Fuel spray breakup model & KHRT \\
Combustion model & Coherent Flame Model \\
Self-ignition model & Two-Stage \\
Nitrogen oxide model & Extended Zeldovich+prompt+fuel \\
Soot model & Kinetic Model \\
\hline
\end{tabular}




\section{Combustion Simulation Results and Analysis}

Figure 3, Figure 4, Figure 5, Figure 6 and Figure 7 show the cylinder pressure, average cylinder temperature, heat release rate and cumulative heat release, NO mass fraction and soot mass fraction under four conditions of different ethanol distribution proportions during the two-stage injection.

\subsection{Cylinder Pressure}

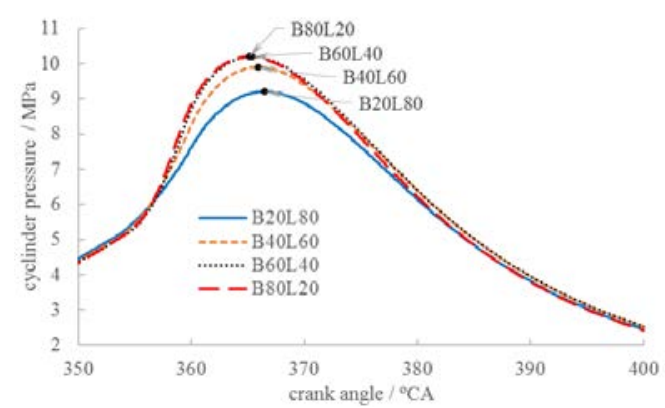

Figure 3 Cylinder Pressure

Figure 3 shows that, the more the ethanol injection during the first stage is, the faster the cylinder pressure rise, and the higher the maximum combustion pressure, and the headmost the corresponding phase are. When the ethanol injection becomes bigger during the first stage, the cylinder pressure curve difference is very small, and B60L40 and B80L20 cylinder pressure curves coincide before $370^{\circ} \mathrm{CA}$, and that of B80L20 is slightly lower afterwards. More ethanol injection during the first stage makes more ethanol volatile, gasify and form more mixture. After diesel burning, the surrounding mixed ethanol is quickly ignited, in addition, due to high ethanol combustion speed and faster flame spreading, the heat and cylinder pressure rise quickly.

\subsection{Average Temperature in the Cylinder}

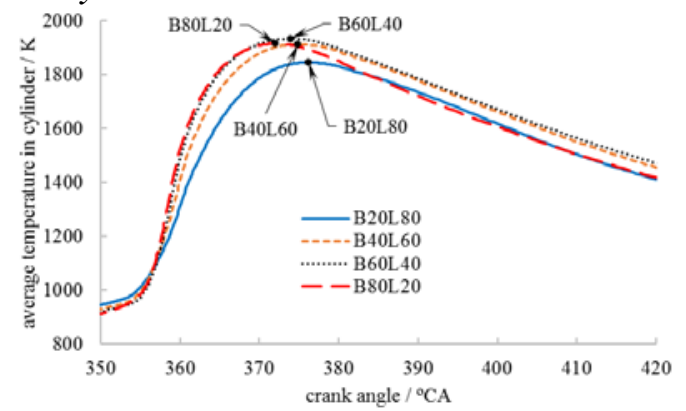

Figure 4 average cylinder temperature

As shown in Figure 4, the more the ethanol injection during the first stage is, the lower the average cylinder temperature is before ignition, but the more quickly cylinder temperature rises and the headmost the corresponding crankshaft rotation is. The highest average temperature in the cylinder of B80L20, B60L40 and B40L60 is relatively close, and that of B60L40 is the highest. During the post-combustion stage, the temperature of B60L40 is similar to that of B40L60, which is higher, and the temperature of B20L80 is similar to that of B80L20, which is lower than that in other two conditions. This shows that the combustion of B20L80 and B80L20 in the postcombustion stage is not as sufficient as that of other two conditions. 
3.3 Heat Release Rate and Accumulated Heat Release

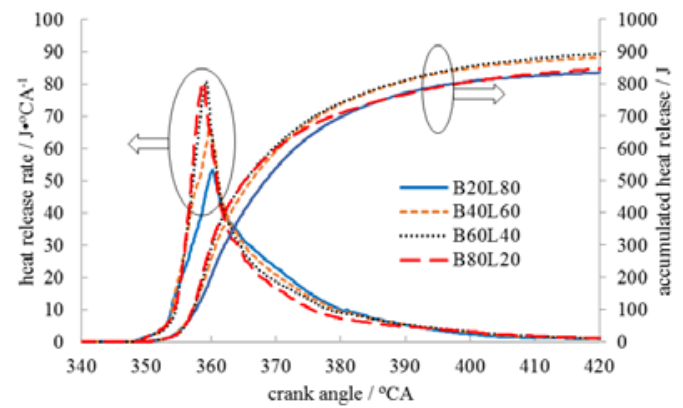

Figure 5 Heat Release Rate and Cumulative Heat Release

Figure 5 shows that, the more the ethanol injection during the first stage is, the steeper the heat release rate curve, the headmost the corresponding phase, and the shorter the duration of the obvious heat release are. During the post-combustion period, the heat release curves coincide. The trend of the cumulative heat release is similar to the average cylinder temperature. The more the ethanol injection during the first stage is, the higher the initial cumulative heat release is. During the post-combustion period, the cumulative heat release of B60L40 is similar to that of B40L60 and the value is higher. While the cumulative heat release of B80L20 is close to that of B20L80 and the value is lower. The cumulative heat release determines the average cylinder temperature to a larger extent.

The cylinder pressure, average cylinder temperature, heat release rate and cumulative heat release shown in Figure 3, Figure 4 and Figure 5 show that, for B60L40 and B40L60, the cylinder combustion pressure and average temperature are higher, the combustion speed is faster, and the combustion is sufficient, indicating that, when the ethanol injection during the first stage has a moderate proportion, the combustion process is better.

\subsection{NO Concentration}

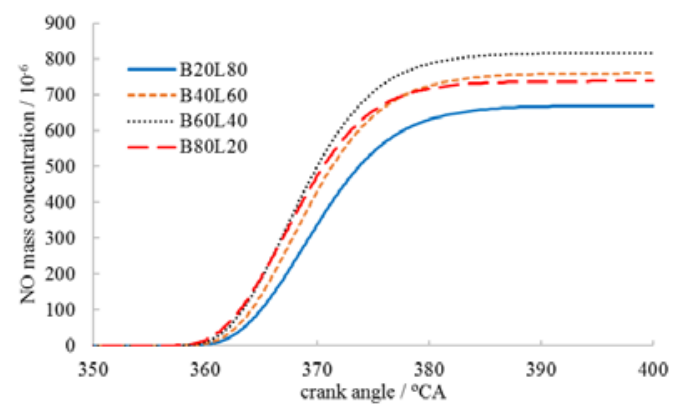

Figure 6 Average NO Mass Concentration in the Cylinder

Figure 6 shows that, B60L40 has the highest NO concentration, followed by B40L60. The NO concentration of B80L20 is slightly lower than that of B40L60, and the value of B20L80 is the lowest. Through comparison with Figure 4, it can be found out that, NO concentration is related to the highest average cylinder temperature and the temperature during the post-combustion stage, and if both of which are high, NO generation is more. The highest average cylinder temperature of B40L60 and B80L20 is almost the same, but as the temperature during the post-combustion stage of B40L60 is higher, NO generation of B40L60 is slightly more.

\subsection{Soot Concentration}

The NO concentration in Figure 6 and soot concentration in Figure 7 show that, more NO generation brings less soot generation. The NO generation condition is high temperature and rick oxygen, while the soot generation condition is high temperature and oxygen deprivation. Viewing from the condition in front of $380^{\circ} \mathrm{CA}$, more ethanol injection during the first stage brings less soot generation. However, after that, with regard to B40L60 and B60L40, the cylinder shall form the temperature and oxygen concentration conditions facilitating soot decomposition in the area with higher soot content, and the soot is decomposed and releases heat, and this heat release part increases the cumulative heat release. 
With regard to four conditions, only B40L60 and B60L40 have soot decomposition, and we will increase examples and analyze its causes in details in the follow-up study.

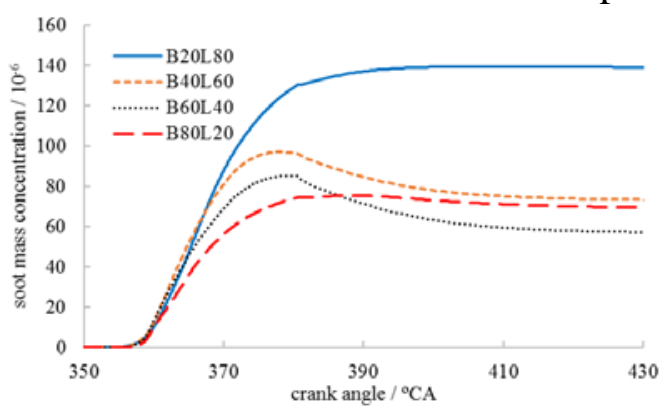

Figure 7 Average Soot Mass Concentration in the Cylinder

\subsection{Discussion and Analysis}

During the first stage of ethanol injection, the piston is in the lower position, the cylinder pressure and temperature are lower, and air resistance of ethanol spray is low, so the spray cone is small, its penetration speed is high and the gasification is slightly slow, thus easily leading to wall interaction [11]. The ethanol mass fraction (extracted from the Section B in Figure 1) of 4 conditions at $260^{\circ} \mathrm{CA}$ are shown in Figure 8. Because of the limitation of the injection angle of all nozzles, the ethanol spray is mainly injected at the cylinder wall and top ring surface of the piston. With the upward movement of the piston and air movement in the cylinder, ethanol spray is gradually diffused and mixed in the cylinder [12].
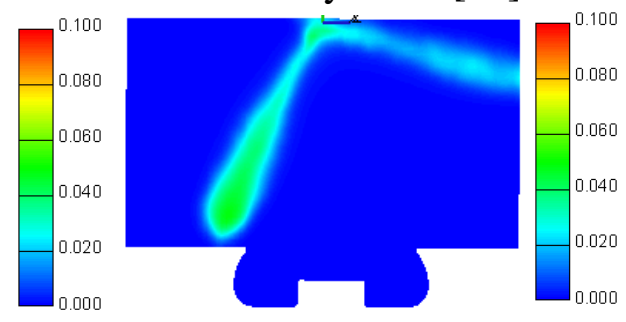

a) B20L80
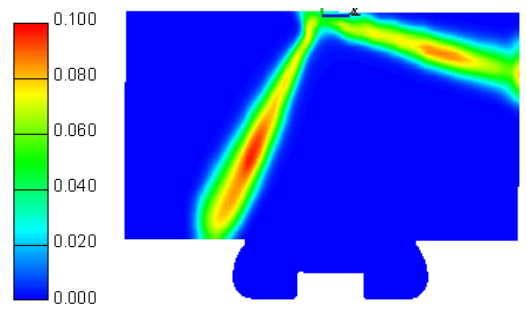

c) B60L40

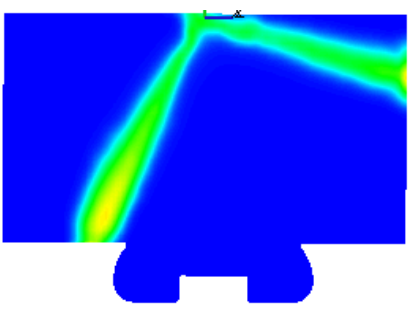

b) B40L60
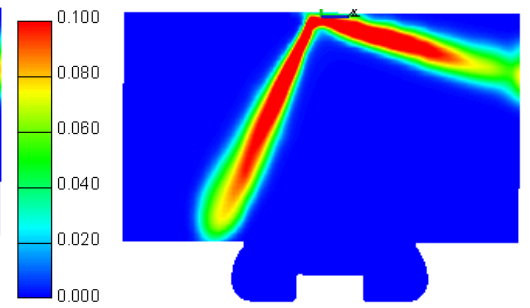

d) B80L20

Figure 8 Ethanol Mass Fraction in the Cylinder at $260^{\circ} \mathrm{CA}$

Figure 9 shows ethanol mass fraction in the cylinder at $344^{\circ} \mathrm{CA}$ and $360^{\circ} \mathrm{CA}$ and diesel mass fraction in the cylinder at $380^{\circ} \mathrm{CA}$. Figure 10 shows ignition time and temperature distribution in the cylinder at $360^{\circ} \mathrm{CA}$ and $380^{\circ} \mathrm{CA}$.

Through comparison with ethanol distribution at $344^{\circ} \mathrm{CA}$ shown in Figure 9, it shows that, there is a higher ethanol concentration area at the top ring surface of the piston, a moderate concentration of mixed ethanol is formed in the $\omega$ combustion chamber, and more ethanol during the first stage also brings higher ethanol concentration. In this case, the injection of ethanol and diesel during the second stage will start soon.

Figure 10 shows that, more ethanol injection during the first stage brings more heat absorbed by ethanol gasification, slightly lower temperature in the cylinder, longer ignition delay period of diesel, and slightly delayed ignition starting point $(1,200 \mathrm{~K}$ temperature area in the cylinder is made as a burning symbol) [13]. The earliest burning area is located in the central area out of the diesel spray and near the $\omega$ combustion chamber. 
Through comparison with the ethanol distribution at $360^{\circ} \mathrm{CA}$ in Figure 9, temperature distribution at $360^{\circ} \mathrm{CA}$ in Figure 10 and heat release rate curve in Figure 5, it can be found out that, the heat release rate peak is close to $360^{\circ} \mathrm{CA}$, large amount of premixed ethanol injected during the first stage in the $\omega$ combustion chamber has been burnt, sprayed ethanol during the second stage is mainly concentrated in the $\omega$ combustion chamber, and more ethanol injection during the first stage brings the highest temperature in the cylinder at $360^{\circ} \mathrm{CA}$.

With regard to B20L80, due to little ethanol injection during the first stage, the heat release rate during the early combustion period is low, and the cylinder temperature and pressure rise slowly. However, as ethanol and diesel sprayed during the second stage are concentrated in the $\omega$ combustion chamber, ethanol and diesel are mixed with air and affect each other. In addition, as the temperature in the cylinder is low and a large number of ethanol suffers gasification and heat absorption, the diesel evaporation and atomization process become slow. As the ethanol combustion consumes more oxygen, there exists the area with insufficient oxygen concentration, thus causing insufficient diesel combustion and soot increase further [14]. In addition, due to lower average cylinder temperature, NO generation is less. The distribution of diesel components at $380^{\circ} \mathrm{CA}$ shows that, B20L80 has the highest diesel components in the $\omega$ combustion chamber, and more diesel participates in the diffusion combustion during the post-combustion period.

With regard to B80L20, as the ethanol injection during the first stage is more, the mixed ethanol quickly burns immediately after the ignition, thus the disturbance to air flow in the cylinder is more serious, and more diesel spray is brought to the top surface of the piston by high-speed airflow (see Figure $9 \mathrm{~d}$ ). Low temperature of the area is not conducive to the diesel combustion. In addition, due to less ethanol injection during the second stage, the heat release is small, thus making the temperature of the $\omega$ combustion chamber during the post-combustion stage lower (Figure 10d), and bringing slower diesel diffusion process and incomplete combustion [15].

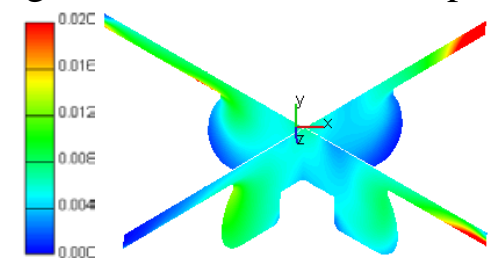

$344^{\circ} \mathrm{CA}$ ethanol fraction

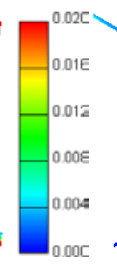

\section{$360^{\circ} \mathrm{CA}$}

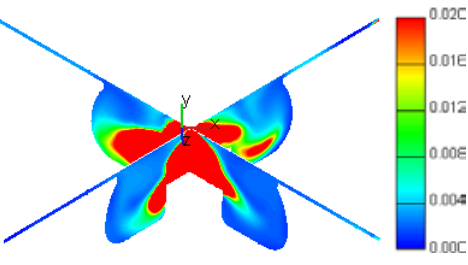

fraction

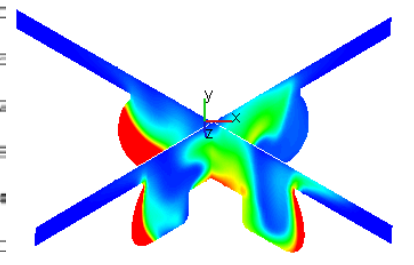

$380^{\circ} \mathrm{CA}$ diesel

a) B20L80

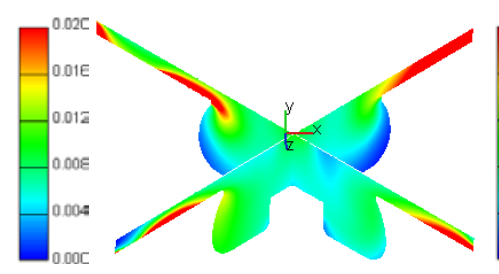

$344^{\circ} \mathrm{CA}$ ethanol fraction

$360^{\circ} \mathrm{CA}$ ethanol fraction

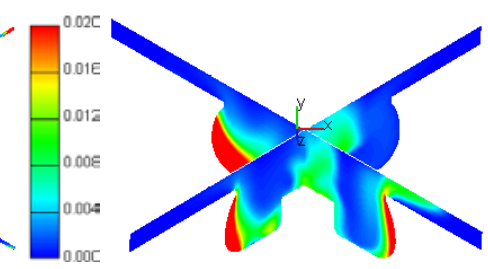

$380^{\circ} \mathrm{CA}$ diesel fraction

b) B40L60

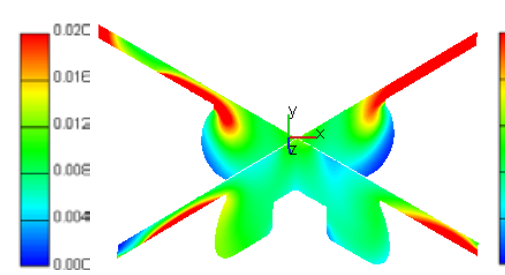

$344^{\circ} \mathrm{CA}$ ethanol fraction

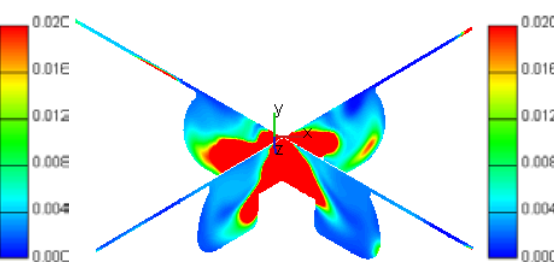




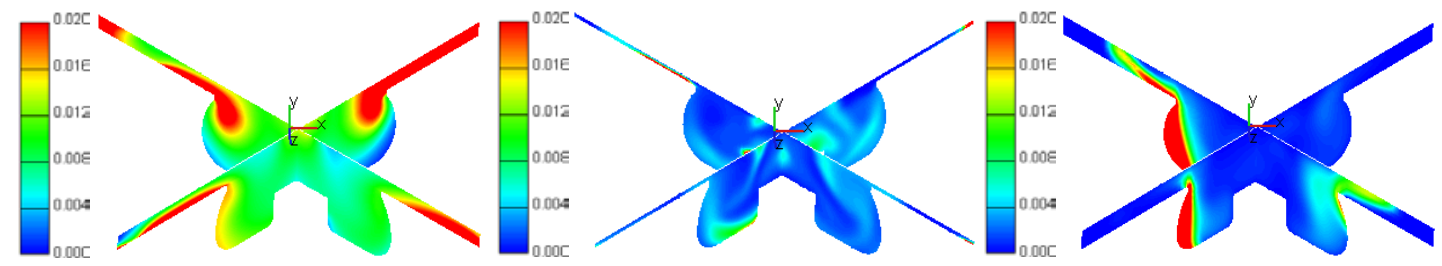

$344^{\circ} \mathrm{CA}$ ethanol fraction

$360^{\circ} \mathrm{CA}$ ethanol fraction

$380^{\circ} \mathrm{CA}$ diesel fraction

d) B80L20

Figure 9 Ethanol Mass Fraction in the Cylinder at $344^{\circ} \mathrm{CA}$ and $360^{\circ} \mathrm{CA}$ and Diesel Mass Fraction in the Cylinder at $380^{\circ}$

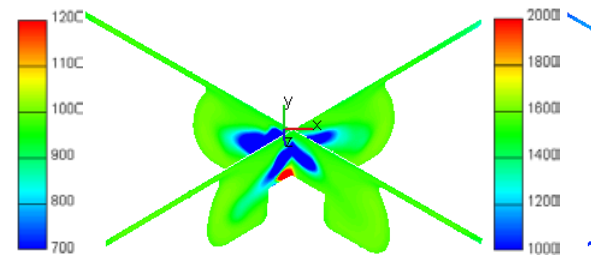

$352^{\circ} \mathrm{CA}$

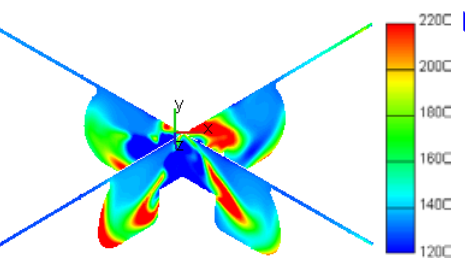

$360^{\circ} \mathrm{CA}$

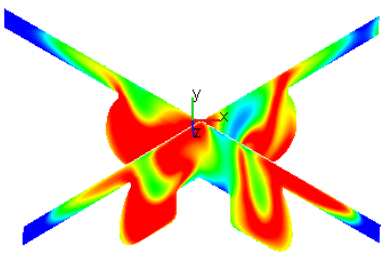

$380^{\circ} \mathrm{CA}$

a) B20L80

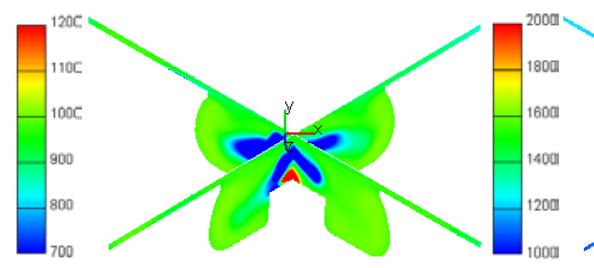

$352.5^{\circ} \mathrm{CA}$

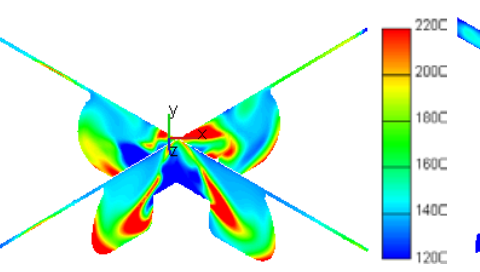

$360^{\circ} \mathrm{CA}$

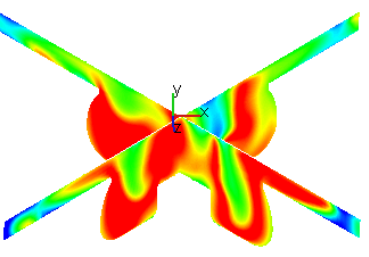

$380^{\circ} \mathrm{CA}$

b) B40L60

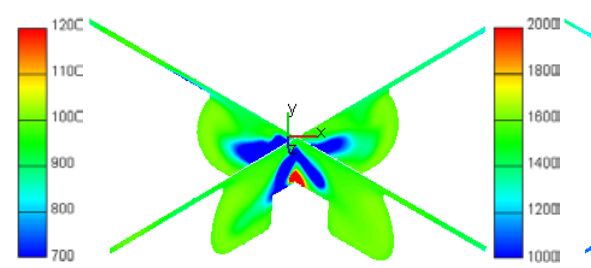

$353^{\circ} \mathrm{CA}$

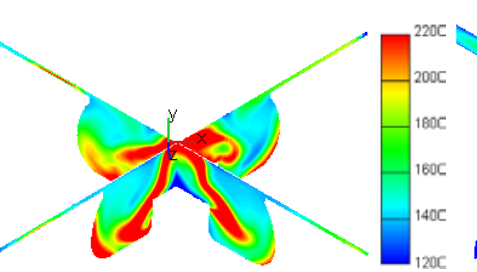

$360^{\circ} \mathrm{CA}$

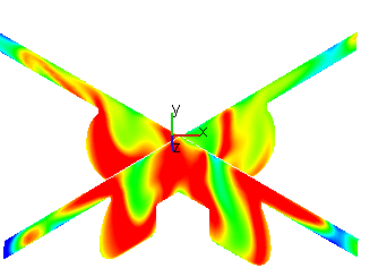

$380^{\circ} \mathrm{CA}$

c) $\mathrm{B} 60 \mathrm{~L} 40$

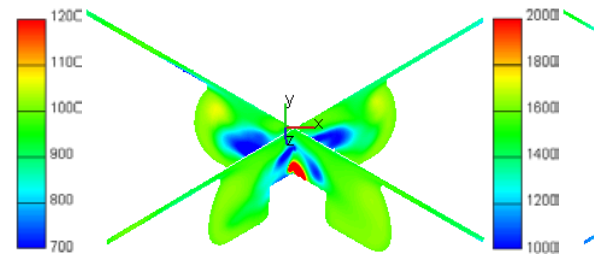

$353.5^{\circ} \mathrm{CA}$

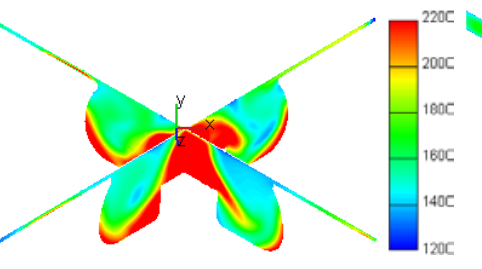

$360^{\circ} \mathrm{CA}$

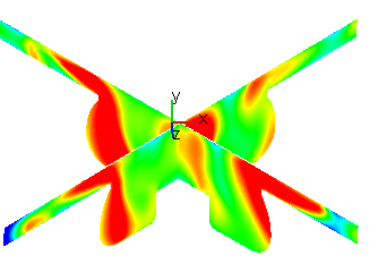

$380^{\circ} \mathrm{CA}$

d) B80L20

Figure 10 . Temperature distribution at the ignition starting point, $360^{\circ} \mathrm{CA}$ and $380^{\circ} \mathrm{CA}$

\section{Conclusion}

Four conditions featured by the same total two-stage ethanol injection and different injection proportions in the first stage and second stage are calculated and analyzed with the established 3D 
combustion model. Based on the characteristics of referenced engine parameters of the model, the following conclusions can be drawn:

(1) With regard to B60L40 and B40L60, the cylinder combustion pressure is higher, the average temperature is bigger, the combustion speed is faster, the combustion is more sufficient, and the combustion process is better.

(2) B60L40 has the highest NO generation while the lowest soot generation, and B20L80 has the lowest NO generation while the highest soot generation, thus reflecting the trend featured by the higher NO generation while the lower soot generation.

(3) In case of B60L40 and B40L60, soot decomposition occurs during the post-combustion stage, therefore, this needs in-depth study.

\section{Acknowledgments}

This research is funded by the National Natural Science Foundation of China (No.51366002) and key project of educational science planning of Guizhou Provincial Education Department (No.2014A065) and key construction projects of the first class University (phase I) of Guizhou Province in 2017- the first class course. Special thanks should go to Liying Zhou who is the corresponding author of this paper.

\section{References}

[1] Jikun Huang, Huangguang Qiu, Michiel Keyzer, et al. Impacts of bioethanol development on China's regional agricultural development [J]. China Ecomomic Quarterly, 2009,8(2):727-742. (in Chinese with English abstract)

[2] Wang Xiaojuan, Feng Hao, Wang Bin, et al. Investigation of two-step pretreatment method for production of ethanol from lignocellulosic biomass [J]. Transactions of the Chinese Society of Agricultural Engineering, 2012, 2012,28(5):194-200. (in Chinese with English abstract)

[3] Fu Chang, Wu Fangwei. The estimation of producing potential of fuel ethanol and its developing strategy in china [J]. Journal of Natural Resources, 2014,29(8):1430-1440. (in Chinese with English abstract)

[4] KRG And, GJ Suppes. Miscibility of ethanol in diesel fuels [J]. Industrial \& Engineering Chemistry Research, 2001, 40(3):949-956.

[5] Datta A, Mandal B K. Impact of alcohol addition to diesel on the performance combustion and emissions of a compression ignition engine [J]. Applied Thermal Engineering,2016,98:670-682.

[6] He Bangquan, Wang Jianxin, Yan Xiaoguang, et al. Combustion and emission characteristics of engines using ethanol-diesel fuels blended on line [J]. Journal of Tsinghua University Science and Technology, 2003，43(11):1523-1525,1541. (in Chinese with English abstract)

[7] Ma Yupo, Liu Fushui, He Xu, et al. Visualization of combustion characteristics of intake port injected ethanol ignited by diesel fuel [J]. Transactions of CSICE,2014,32(4):296-301. (in Chinese with English abstract)

[8] S Natarajan, MA Kumar, AUM Sundareswaran. Computational analysis of an early direct injected HCCI engine using bio ethanol and diesel blends as fuel [J]. Energy Procedia, 2017,105:350-357.

[9] Fang Xianzhong, Liu Xunjun, Liu Zhongchang, et al. Performance comparison between diesel-methanol injection and diesel-ethanol injection with dual injection system in a DI compression ignition engine [J]. Transactions of CSICE,2004,22(6):514-517. (in Chinese with English abstract) 
[10] Fang Xianzhong, Liu Xunjun, Li Guoliang, et al. Development of compression ignition test engine with dual direct injection systems [J]. Journal of Jilin University (Engineering and Technology Edition ), 2005,35(1):34-38. (in Chinese with English abstract)

[11] L.-Y. Zhou, S.-F. Dong, H.-F. Cui, et al. Measurements and analyses on the transient discharge coefficient of each nozzle hole of multi-hole diesel injector [J]. Sensors \& Actuators: A. Physical,2016,244: 198-205.

[12] M. Farias, J. F. Schlosser, A. Russini, et al. Performance of an agricultural engine using mineral diesel and ethanol fuels [J]. Ciencia Rural, 2017, 47(3):1-6.

[13] W Tutak, A Jamrozik, M Pyrc, et al. A comparative study of co-combustion process of dieselethanol and biodiesel-ethanol blends in the direct injection diesel engine [J]. Applied Thermal Engineering, 2017,117:155-163.

[14] Prashant G K, Lata D B, Joshi P C. Investigations on the effect of ethanol blend on the combustion parameters of dual fuel diesel engine[J]. Applied Thermal Engineering,2016,96:623631.

[15] CD Rakopoulos, KA Antonopoulos, DC Rakopoulos, et al. Multi-zone modeling of combustion and emissions formation in DI diesel engine operating on ethanol-diesel fuel blends [J]. Energy Conversion \& Management, 2008,49(4):625-643. 